\title{
Study of Health Behaviours and Lifestyle Characterstics among Medical Students at Al-Azhar University, Assuit Branch
}

\author{
AMR A. FAHMY, M.Sc.; MOHAMED NAGUIB A. MOHAMED, M.D.; \\ HAMED O. KHALIFA, M.D. and ABD-ELNASER SHAIBAT EL-HAMD MOHAMED, M.D.
}

The Department of Public Health and Community Medicine, Faculty of Medicine, Al-Azhar University

\begin{abstract}
Background: Lifestyle is the way of living of individuals, families, and societies which can be healthy or unhealthy in terms of personal behaviors such as nutrition, physical activity, and stress management. A healthy lifestyle may result in better health and happiness, and in contrast, an unhealthy lifestyle may cause illness and morbidity.

Aim of Study: To find out the relationship between healthy lifestyle behavior variables of the study sample and students' sex and university years.

Patients and Methods: A cross sectional study was carried out enrolling 426 students data were collected using interview questionnaire it consists two following sections: (1) Personal data: Age, sex, university year, living place, working status, family income, number of family member, Father's education, and mother's education, (2) Healthy lifestyle behaviors: It included seven variables: Smoking habit, dietary habits, physical exercise and self-health habits, spend free time, taking non-prescribed drugs in last month, and sleeping pattern. Period of the study from May 2019 up to the end of March 2021.

Results: The mean age of the total samples was $21.5 \pm 1.5$ years. The majority $(76.1 \%)$ were males. The students in the age group (20-24) years had the highest percentage (85.9\%), while the students in the age group (-20 years) had the lowest proportion $(3.3 \%)$. There was no statistically significant difference in age between male and female students. The majority of students in the final year $(45 \%)$ were males $(40.1 \%)$ and females $(4.9 \%)$, with the difference being statistically significant.
\end{abstract}

This study revealed that $67.6 \%$ of students reported they had average family income, $70.1 \%$ and $58.8 \%$ of male and female students respectively were eating breakfast regularly, $76.6 \%$ of the second grade were eating breakfast regularly, $69.4 \%$ of male students were physically active, $76.6 \%$ of the second grade were practicing exercise routinely, $82.1 \%$ of male students perform dental examination in the last year.

Conclusion: $67.1 \%$ of students were living in students hostel, male students were eating breakfast and meat and fish regularly more than female, male students were physically

Correspondence to: Dr. Amr A. Fahmy Ahmed, E-Mail: amr alifahmy1717@gmail.com active more than female, $76.6 \%$ of the second grade were actively exercise than other grades.

Key Words: University students - Lifestyle - Healthy behaviours.

\section{Introduction}

LIFESTYLE is the way of living of individuals, families, and societies which can be healthy or unhealthy in terms of personal behaviors such as nutrition, physical activity, and stress management. A healthy lifestyle may result in better health and happiness, and in contrast, an unhealthy lifestyle may cause illness and morbidity [1]

The health promoting behaviuors, as one of the major criteria that determines health, are known as one important demographic factor in the avoidance of many illnesses, and health promotion and disease prevention are directly associated with these behaviors. Some of the most important health promotion behaviuors involve nutrition, regular exercise, avoidance of destructive behaviors and drugs, protection against accidents, timely detection of disease symptoms from the physical aspect, controlling emotions, feelings and thoughts and coping with stress and mental problems, and adjusting the interpersonal relations from the social aspect [2]

Un healthy habits introduced during young adulthood usually persist in later life and can increase the risk of several chronic diseases. In a survey in a college population, $36 \%$ respondents revealed that time constraints posed a barrier to adoption of healthy practices. Initiation of unhealthy behaviours in medical students may be ascribed to peer pressure, mental stress, performance anxiety in a competitive academic environment, sociocultural adjustment problems, inadequate parental supervision, home sickness after leaving their 
parental homes, and greater financial autonomy as compared to their earlier years. Since their behaviours are amenable to change, studentship is particularly the right period for educational interventions regarding the importance of developing and maintaining healthy behavior [3]

Unhealthy lifestyles characterized by physical inactivity, poor diet, tobacco smoking and excessive alcohol use, as well as mental ill health, are seen as the main risk factors for chronic diseases and premature deaths [4]. In combination, they account for a significant amount of preventable deaths worldwide, with tobacco smoking alone claiming 6 million annual deaths, physical inactivity 3.2 million, harmful alcohol use 2.3 million, overweight and obesity 2.8 millionand dietary risks 11.3 million [5].

Statistics indicate that $53 \%$ of the causes of Death are related to human lifestyle. Due to unhealthy lifestyle, there is happened a great increase in the prevalence and incidence of many chronic conditions, including obesity, atherosclerosis, and coronary heart disease (CHD) [6]

Unhealthy lifestyle behaviours are modifiable and usually established during youth or young adulthood. Furthermore, being overweight and obesity in youth are powerful indicators of being overweight in adulthood and related disease. Despite the widely-documented consequences associated with unhealthy lifestyle behaviours, globally, a substantial proportion of young adults, notably university students, engage in unhealthy lifestyle practices [7].

Healthy lifestyle behaviors are those behaviors that demonstrate responsibility for one's own health, taking part in physical activity, having adequate nutritional intake, realizing self-actualization, establishing interpersonal relations, and learning how to manage stress [8].

The aim of the present study was to find out the relationship between healthy lifestyle behaviuor variables of the study sample and students'sex and university years.

\section{Patients and Methods}

The present study deals with "Study of Health Behaviours and Lifestyle Characterstics among Medical Students at Al-Azhar University, Assuit Branch".

This was a descriptive cross-sectional study. The study included students of (Faculty of Medicine for boys and girls) at Al-Azhar University, Assuit branch, Assuit Governorate; who attending during the study period.

The present cross-sectional study was conducted at Faculty of Medicine for boys and girls at AlAzhar University, Assiut branch during academic year 2019/2020.

The study was conducted from May 2019 up to the end of March 2021 and passed through the following phases:

1- Preparatory phase:During this phase the following steps were done:

\section{Survey of literature:}

It took about 4 months during the period from (first of May 2019) to (the end of August 2019). During this phase, the following items were covered:

- Lifestyle behaviors:

- Definition of lifestyle.

- What lifestyle factors mean?

- Lifestyle factors and diseases.

- How do lifestyle factors affect health?

- Impact of lifestyle behaviors on youth and society.

- Healthy lifestyle behaviors.

- Relationship between lifestyle behaviors and quality of life.

Some lifestyle behaviors:

- Smoking.

- What smoking means?

- What are types of smoking?

- Are there any benefits to smoking?

- Hazards of smoking:

- Smoking behaviors and health status

- Prevalence of smoking behaviors among university students:

- Impact of smoking behaviors on quality of life of university students:

- Smoking cessation:

- Benefits of stopping smoking.

- Dietary habits:

- What is the dietary plate?

- A Healthy Dietary Pattern.

- Healthy food.

- Unhealthy food.

- Impact of diet on health status and society.

- Recommendations about consumption of healthy diet. 
- Dietary recommendations for fiber.

- Consumption of food patterns among students.

- Physical activity:

- Definition of Physical activity.

- Types of Physical activity.

- Levels of Physical Activity.

- Physical Activity Intensity.

- Importance of physical activity.

- Prevalence of Physical activity among students.

- Effect of Regular exercise and physical activity on our health status.

- Hazards of physical inactivity.

- Recommendations for practices Physical activity.

- Overweight and obesity:

- Introduction \& Prevalence of obesity.

- Definition.

- Causes:

- Classifications.

- Effect of obesity on health:

- Recommendations of WHO about prevention of obesity.

- Sleep pattern:

- Introductions.

- Definition.

- Evolution of sleep patterns across the lifespan

- Development patterns and changes with aging:

- Effect of sleep pattern on health of medical university students.

- Recommendations for sleep duration.

- Tooth brush:

- Introductions.

- Definition.

- Types of toothbrush.

- Toothbrush and health.

- Recommendations for regular toothbrush.

- Leisure time:

- Definition:

- Leisure activities and health.

- Leisure time \& students.

- Hand washing:

- Definition.

- Hand washing and health:

- Recommendations for hand washing.
The review of literature was based on:

A survey of literature was based on: Libraries of the Faculties of Medicine for boys \& girls at Al-Azhar University, Assuit branch. Recent text books and some previous researches. Periodic medical journals and WHO reports \& publications. Computer research on different internet trusted sites. Reports from Ministry of Health in Egypt.

Administrative consideration: A formal approval was taken from the dean of each faculty or the corresponding administrator to facilitate the work of the study.

Ethical considerations: An informal Verbal consent was taken from the respondents with simple explanation about the aim of the study and emphasis that personal and other data would be used for scientific work only. Acover page describing the aim and confidentiality of the work was included in the questionnaire.

Inclusion criteria: All students of faculty of medicine for boys \& girls at Al-Azhar University, Assuit branch; who also gave verbal consent to participate in the study voluntarily.

Exclusion criteria: Students at first grade of faculty of medicine for boys \& girls at Al-Azhar University, Assuit branch because they have not been to university for a long time; they are less affected by their lifestyle choices.

Tools of data collection (research tools):

Data were collected by two tools:

I- Interview questionnaire was used for data collection. It was taken two weeks (frist two weeks of Sebtember 2019). It has two sections:

Personal data:

It included the following items:

- Age: The age was collected as a quantitative variable to estimate the mean age of the sample then classified into three categories (less than 20 years, from 20-24 years, and more than 24 years.

- Sex: Male or female.

- University years: (Second - third - final).

- Living place: With family, student's hostel, with friends and living alone.

- Working status: Not working and working.

- Family income: Equal to expenditures, higher than expenditures and lower than expenditures.

- Number of family member: Less than 3, 3-5 and more than 5 persons. 
- Father's education: Read and write primary, secondary and high education.

- Mother's education: Read and write primary, secondary and high education.

\section{Healthy lifestyle behaviors:}

It included seven variables: Smoking habit, dietary habits, physical exercise, and self-health habits, spend free time, taking non-prescribed drugs in last month and sleeping pattern.

\section{Dietary habits:}

This included the following ten habits: (a) Eating breakfast regularly, (b) Limit usage of sugar or sweets, (c) Take excess salts in food, (d) Eat fried food, (e) Eat fresh vegetables, (f) Eat fruits, (g) Eat meat and fish, (h) Eating street food, (i) Drinking excess tea and coffee, and (j) Drinking soda.

\section{Physical exercise:}

Some examples of physical exercise are running, swimming, walking, biking, and other sporting practices.

\section{Self-health habits:}

This included the following four habits, (a) Dental exam in last year, (b) Using of tooth brush, (c) Eye exam in last year and (d) Flu vaccination in last year.

\section{Spending free time:}

As, participate in trips, social activities, the time spent at home like watching TV, reading, visiting relatives and friends, video games and so on.

\section{II- Clinical assessment of following measurements:}

BMI was used as a health outcome that affected by dietary habits, physical exercise and life style [9]. In our study we considered BMI is an important indicator for obesity prevalence among large populations and generally, reflects the degree of fitness among individuals. And was measured by body mass index (BMI) calculated from the equation: $\mathrm{BMI}=$ Weight (in kilograms) / squared height (in meters) and categorized, according to Wang and Coups [9] classification, into: Underweight: BMI $<18.5$, Normal weight: BMI 18.5-24.9, and Overweight: BMI 25-29.9, Obese: BMI >30.

\section{Sampling:}

\section{I- Sample design:}

A- The Target Population: The target population of the study was the students of (Faculty of Med- icine for boys and girls) at Al-Azhar University, Assuit branch, Assuit Governorate; who attending during the study period.

$B$ - Sample frame: The sample frame of students was obtained from students affairs. They were originally classified into 6 strata representing the different academic years of faculties of medicine.

$C$ - College students' population: The total number of the students' population of (Faculty of Medicine for boys and girls) at Al-Azhar University, Assuit branch for the academic year (2019-2020) was 1100 , consisting of 811 male students and 289 female students.

D-Sample Technique: Astratified random sample technique was being conducted. Representative sample was obtained from each stratum. The selected participants from each stratum were being chosen using simple random sample technique. A structured questionnaire was be used to collect data from students who accepted to participate in the study.

E-Sample Size: The sample size was calculated using (Epi-Info version 7) based on the following assumption: (1) Total number of the students' population (with exception of first grade students) of faculty of medicine for boys \& girls for the academic year 2019/2020 and (2) Confidence level $95 \%$.

The estimated sample size of students was (426) calculated by (Epi-Info version 7).

The sample size of students (426 students) from (Faculty of Medicine for boys and girls) according to the proportion of total number of the students' population (with exception of first grade students) in each faculty to total number of the students' population of both faculties.

Asthe same manner, we selected randomly participants from each grade according to their proportion to total number of students (with exception of first grade students) atthis college, and all the chosen students were included in the our study.

Data collection: The study was conducted during academic year 2019/2020. This phase lasts about 5 months (from first of October 2019 to end of February 2020). Data were collected using the previously constructed interview questionnaire. Each interview session lasted about 25 minutes on the average. More than one session was needed to complete the interview questionnaire.It necessitates the researcher to visit the research setting four visits per week at different hours of the day to ensure meeting the selected students. The period 
of data collection was expanded for this 5 months period to accommodate with the nature of study within college of medicine that differs regarding different grades.

\section{Evaluation phase:}

This phase took about 7 months (between the first of March 2020 to end of September 2020).

\section{Statistical analysis:}

The collected data were coded, processed and analyzed using the SPSS (Statistical Package for Social Sciences) version 22 for Windows $®$ (IBM SPSS Inc, Chicago, IL, USA). The mean was used as a measure of central tendency. The standard deviation was used as a measure of dispersion. Chi-square $(\chi 2)$ was used to indicate presence or absence of a statistically significant difference among the studied variables. $p$-value $<0.05$ was considered significant.

Binomial logistic regression analysis was done to predict the relation between different studied variables: (Smoking habits, dietary habits, physical exercise, self-health habits, spend free time, taking non prescribed drugs and sleeping pattern) and measures of BMI.

Also binomial logistic regression analysis was done to predict the relation between different studied variables: (Smoking habits, dietary habits, physical exercise, self-health habits, spend free time, taking non prescribed drugs and sleeping pattern) and measures of health outcome.

\section{Results}

The highest percentage $(85.9 \%)$ of the students was in the age group (20-24) years and the lowest percentage $(3.3 \%)$ was in the age group ( $<20$ years). No statistically significant difference between students' males and females regarding to age. The majorities $(45 \%)$ of the total students were in the final year, $(40.1 \%)$ were males and $(4.9 \%)$ were females, the difference was statistically significant regarding to university years. As regard living place, more than two third of the total students $(67.1 \%)$ were living in students hostel, while $(2.1 \%)$ of them were living alone, the difference was statistically significant between students male and females. Regarding to working status, the lowest percentage $(20.9 \%)$ they worked beside study $(19.5 \%)$ were males and $(1.4 \%)$ were females, and the difference was statistically significant.

Around two third of students (67.6\%) reported they had average family income and $(5.9 \%)$ of them reported insufficient family income, while $(87.5 \%)$ of the students had family size consisted of (3-5) members, while (1.2\%) were less than 3 members, the difference was statistically significant. On the other hand, there is no statistically significant difference between male and female students regarding their parent's education (Table 1).

The highest percentage of male and female students who used to eating breakfast regularly was $(70.1 \%)$ and $(58.8 \%)$, respectively, while the lowest percentage among male and female students who did not used to eating breakfast regularly $(7.4 \%)$ and $(5.9 \%)$ respectively, the difference was statistically significant. The percentage between male and female students who used to routinely eat limit amounts of sugar or sweets was $(67.3 \%)$ and $(55.9 \%)$, respectively, while the percentage between male and female students who did not use sugar or sweets was $(9.0 \%)$ and $(3.9 \%)$ respectively, the difference was statistically significant. On the other hand the majorityof male and femalestudents reported that they were avoiding use excess salt in food was $(66.7 \%) \&(61.8 \%)$ respectively, whilesmall proportion of male and femalestudents who reported that they using excess salt in food was $(8.0 \%) \&(2.0 \%)$ respectively, the difference was statistically significant.

Therewas no statistically significant difference between male and female students regarding to eating fried food. Moreover there was statistically significant difference between males and females students regarding to eating fresh vegetables and $\&$ fruits routinely. The percentage of male students of study sample who were eating meat and fish routinely was $(46.9 \%)$, while in female students was $(53.9 \%)$ without statistically significant difference (Table 2).

The percentage of students who used to eat breakfast regularly was higher among students of the second grade $(76.6 \%)$, compared to the students of the third grade $(62.9 \%)$ and the final grade $(63.0 \%)$, the difference was statistically significant. The percentage between the study samples who used to routinely eat limit amounts of sugar or sweets was $(75.9 \%)$ among the second grade students, compared to the students of the third grade $(55.7 \%)$ and the final year $(60.9 \%)$, the difference was statistically significant. On the other hand among the study sample, nearly $(74.5 \%)$ of the second grade students reported that they avoided using excess salt in food compared to $(62.9 \%)$ and $(60.4 \%)$ of the study sample for the third grade and the last grade respectively, the difference was statistically significant. 
Table (1): Socio-demographic characteristics of the studied sample.

\begin{tabular}{|c|c|c|c|c|c|c|}
\hline \multirow{2}{*}{ Variable } & \multicolumn{2}{|c|}{ Male } & \multicolumn{2}{|c|}{ Female } & \multicolumn{2}{|c|}{ Total } \\
\hline & No. & $\%$ & No. & $\%$ & No. & $\%$ \\
\hline \multicolumn{7}{|l|}{ Age of student: } \\
\hline$<20$ & 9 & 2.1 & 5 & 1.2 & 14 & 3.3 \\
\hline $20-24$ & 276 & 64.8 & 90 & 21.1 & 366 & 85.9 \\
\hline$>24$ & 39 & 9.2 & 7 & 1.6 & 46 & 10.8 \\
\hline \multirow[t]{2}{*}{ Total } & 324 & 76.1 & 102 & 23.9 & 426 & 100.0 \\
\hline & \multicolumn{6}{|c|}{$\xi^{2}=3.1$} \\
\hline \multicolumn{7}{|l|}{ University year: } \\
\hline Second Grade & 117 & 27.5 & 20 & 4.7 & 137 & 32.2 \\
\hline Third Grade & 36 & 8.5 & 61 & 14.3 & 97 & 22.8 \\
\hline Final Grade & 171 & 40.1 & 21 & 4.9 & 192 & 45.0 \\
\hline \multirow[t]{2}{*}{ Total } & 324 & 76.1 & 102 & 23.9 & 426 & 100.0 \\
\hline & \multicolumn{6}{|c|}{$\xi^{2}=105.2 *$} \\
\hline \multicolumn{7}{|l|}{ Living place: } \\
\hline With Family & 19 & 4.5 & 16 & 3.8 & 35 & 8.3 \\
\hline Students Hostel & 230 & 54.0 & 56 & 13.1 & 286 & 67.1 \\
\hline With Friend & 67 & 15.7 & 29 & 6.8 & 96 & 22.5 \\
\hline Living Alone & 8 & 1.9 & 1 & 0.2 & 9 & 2.1 \\
\hline \multirow[t]{2}{*}{ Total } & 324 & 76.1 & 102 & 23.9 & 426 & 100.0 \\
\hline & \multicolumn{6}{|c|}{$\xi^{2}=15.0^{*}$} \\
\hline \multicolumn{7}{|l|}{ Working status: } \\
\hline Not Working & 241 & 56.6 & 96 & 22.5 & 337 & 79.1 \\
\hline Working & 83 & 19.5 & 6 & 1.4 & 89 & 20.9 \\
\hline \multirow[t]{2}{*}{ Total } & 324 & 76.1 & 102 & 23.9 & 426 & 100.0 \\
\hline & \multicolumn{6}{|c|}{$\xi^{2}=18.3^{*}$} \\
\hline \multicolumn{7}{|l|}{ Family income: } \\
\hline Average Expenditures & 213 & 50.0 & 75 & 17.6 & 288 & 67.6 \\
\hline Higher Than Expenditures & 91 & 21.4 & 22 & 5.2 & 113 & 26.5 \\
\hline Lower Than Expenditures & 20 & 4.7 & 5 & 1.2 & 25 & 5.9 \\
\hline \multirow[t]{2}{*}{ Total } & 324 & 76.1 & 102 & 23.9 & 426 & 100.0 \\
\hline & \multicolumn{6}{|c|}{$\xi^{2}=2.2$} \\
\hline \multicolumn{7}{|l|}{ Number of family member: } \\
\hline Less Than 3 & 3 & 0.7 & 2 & 0.5 & 5 & 1.2 \\
\hline $3-5$ & 295 & 69.2 & 78 & 18.3 & 373 & 87.5 \\
\hline More Than 5 & 26 & 6.1 & 22 & 5.2 & 48 & 11.3 \\
\hline \multirow[t]{2}{*}{ Total } & 324 & 76.1 & 102 & 23.9 & 426 & 100.0 \\
\hline & & & & & & \\
\hline Father's education: & & & & & & \\
\hline Primary & 8 & 1.9 & 4 & 0.9 & 12 & 2.8 \\
\hline Secondary & 73 & 17.1 & 18 & 4.2 & 91 & 21.4 \\
\hline High & 243 & 57.0 & 80 & 18.8 & 323 & 75.8 \\
\hline Total & 324 & & & & & \\
\hline Mother's education: & & 76.1 & 102 & 23.9 & 426 & 100.0 \\
\hline Primary & 13 & 3.1 & 5 & 1.2 & 18 & 4.3 \\
\hline Secondary & 148 & 34.7 & 44 & 10.3 & 192 & 45.0 \\
\hline High & 163 & 38.3 & 53 & 12.4 & 216 & 50.7 \\
\hline Total & 324 & 76.1 & 102 & 23.9 & 426 & 100.0 \\
\hline & & & & & & \\
\hline
\end{tabular}

NB: (*) Statistically significant difference. 
Table (2): Food consumption pattern among the study sample regarding to sex.

\begin{tabular}{|c|c|c|c|c|c|c|}
\hline \multirow{2}{*}{ Variable } & \multicolumn{2}{|c|}{ Male } & \multicolumn{2}{|c|}{ Female } & \multicolumn{2}{|c|}{ Total } \\
\hline & No. & $\%$ & No. & $\%$ & No. & $\%$ \\
\hline \multicolumn{7}{|c|}{ Have breakfast regularly: } \\
\hline Routinely & 227 & 70.1 & 60 & 58.8 & 287 & 67.4 \\
\hline Sometimes & 73 & 22.5 & 36 & 35.3 & 109 & 25.6 \\
\hline Never & 24 & 7.4 & 6 & 5.9 & 30 & 7.0 \\
\hline Total & 324 & 100.0 & 102 & 100.0 & 426 & 100.0 \\
\hline & \multicolumn{6}{|c|}{$\xi^{2}=6.7 *$} \\
\hline \multicolumn{7}{|c|}{ Limit usage of sugar or sweets: } \\
\hline Routinely & 218 & 67.3 & 57 & 55.9 & 275 & 64.6 \\
\hline Sometimes & 77 & 23.7 & 41 & 40.2 & 118 & 27.7 \\
\hline Never & 29 & 9.0 & 4 & 3.9 & 33 & 7.7 \\
\hline Total & 324 & 100.0 & 102 & 100.0 & 426 & 100.0 \\
\hline & \multicolumn{6}{|c|}{$\xi^{2}=11.7 *$} \\
\hline \multicolumn{7}{|c|}{ Take excess salts in food: } \\
\hline Routinely & 26 & 8.0 & 2 & 2.0 & 28 & 6.6 \\
\hline Sometimes & 82 & 25.3 & 37 & 36.2 & 119 & 27.9 \\
\hline Never & 216 & 66.7 & 63 & 61.8 & 279 & 65.5 \\
\hline Total & 324 & 100.0 & 102 & 100.0 & 426 & 100.0 \\
\hline Eat fried food: & \multicolumn{6}{|c|}{$\xi^{2}=8.0 *$} \\
\hline Routinely & 26 & 8.0 & 9 & 8.8 & 35 & 8.2 \\
\hline Sometimes & 87 & 26.9 & 38 & 37.3 & 125 & 29.3 \\
\hline Never & 211 & 65.1 & 55 & 53.9 & 266 & 62.5 \\
\hline \multirow[t]{2}{*}{ Total } & 324 & 100.0 & 102 & 100.0 & 426 & 100.0 \\
\hline & \multicolumn{6}{|c|}{$\xi^{2}=4.5$} \\
\hline \multicolumn{7}{|c|}{ Eat fresh vegetables: } \\
\hline Routinely & 227 & 70.1 & 63 & 61.8 & 290 & 68.1 \\
\hline Sometimes & 71 & 21.9 & 34 & 33.3 & 105 & 24.6 \\
\hline Never & 26 & 8.0 & 5 & 4.9 & 31 & 7.3 \\
\hline \multirow[t]{2}{*}{ Total } & 324 & 100.0 & 102 & 100.0 & 426 & 100.0 \\
\hline & \multirow{2}{*}{\multicolumn{6}{|c|}{$\xi^{2}=6.0^{*}$}} \\
\hline \multicolumn{6}{|l|}{ Eat fruits: } & \\
\hline Routinely & 222 & 68.5 & 64 & 62.7 & 286 & 67.1 \\
\hline Sometimes & 77 & 23.8 & 35 & 34.3 & 112 & 26.3 \\
\hline Never & 25 & 7.7 & 3 & 3.0 & 28 & 6.6 \\
\hline \multirow[t]{2}{*}{ Total } & 324 & 100.0 & 102 & 100.0 & 426 & 100.0 \\
\hline & \multicolumn{6}{|c|}{$\xi^{2}=6.4^{*}$} \\
\hline \multicolumn{7}{|c|}{ Eat meat and fish: } \\
\hline Routinely & 152 & 46.9 & 55 & 53.9 & 207 & 48.6 \\
\hline Sometimes & 145 & 44.8 & 40 & 39.2 & 185 & 43.4 \\
\hline Never & 27 & 8.3 & 7 & 6.9 & 34 & 8.0 \\
\hline \multirow[t]{2}{*}{ Total } & 324 & 100.0 & 102 & 100.0 & 426 & 100.0 \\
\hline & \multicolumn{6}{|c|}{$\xi^{2}=1.5$} \\
\hline
\end{tabular}

NB: (*) Statistically significant difference.

There was no statistically significant difference between students in different university grades regard to eating fried food. About three fourth of the studied sample of second grade students were consuming fresh vegetables \& fruits routinely, on other hand about two third of the students of the third grade and the final grade were consuming fresh vegetables \& fruits routinely, the difference was statistically significant. The percentage of study sample who were never eaten meat and fish was more among students in the final grade $(11.5 \%)$, the difference was statistically significant (Table 3).
Among 277 students, who were engaged in physical activity routinely, the highest percentage $(69.4 \%)$ was found among male students, while less proportion $(51.0 \%)$ among female students, the difference was statistically significant. According to intensity of exercise the percentage of moderate physical exercise was higher among male students $(50.9 \%)$. Compared to $(42.2 \%)$ in female students, the difference was statistically significant (Table 4).

Out of 277 students, who were engaged in physical exerciseroutinely, the highest percentage 
(76.6\%) was found among second grade students, while less proportion (58.9\%) among final grade students, the difference regarding physical exercise was statistically significant. According to intensity of exercise the percentage of vigorous exercise was higher among second grade students (10.9\%) compared to other grades, the difference was statistically insignificant (Table 5).

Most of the male and female students reported that they did not use any type of medicine in last month not prescribed by the physicians, the difference was statistically insignificant. While $(82.1 \%)$ of male students perform dental examination in the last year compared to $(61.8 \%)$ of female students, with statistically significant difference. Regarding using of tooth brush there is statistical significance difference was found between male and female students (Table 6).

Above (90\%) of the different age groups of the studied samples were nonsmokers, the difference was statistically insignificant. The behavior concerned with healthy dietary habits was more prevalent among students under 20 year $(85.7 \%)$ compared to $(66.1 \%)$ of students between 20 and 24 years and $(50.0 \%)$ of students above 24 year with statistical significant difference. The percentage of studied samples who practiced physical exercise was greater among students under 20 year $(78.6 \%)$ compared to $(59.3 \%$ ) among students between 20 and 24 years and $(39.1 \%)$ among students above 24 year with statistical significant difference.

Table (3): Food consumption pattern among the study sample regarding to university years.

\begin{tabular}{|c|c|c|c|c|c|c|c|c|}
\hline \multirow{2}{*}{ Variable } & \multicolumn{2}{|c|}{ Second grade } & \multicolumn{2}{|c|}{ Third grade } & \multicolumn{2}{|c|}{ Final grade } & \multicolumn{2}{|c|}{ Total } \\
\hline & No. & $\%$ & No. & $\%$ & No. & $\%$ & No. & $\%$ \\
\hline \multicolumn{9}{|l|}{ Have breakfast regularly: } \\
\hline Routinely & 105 & 76.6 & 61 & 62.9 & 121 & 63.0 & 287 & 67.4 \\
\hline Sometimes & 23 & 16.8 & 32 & 33.0 & 54 & 28.1 & 109 & 25.6 \\
\hline Never & 9 & 6.6 & 4 & 4.1 & 17 & 8.9 & 30 & 7.0 \\
\hline Total & 137 & 100.0 & 97 & 100.0 & 192 & 100.0 & 426 & 100.0 \\
\hline & \multirow{2}{*}{\multicolumn{8}{|c|}{$\xi^{2}=11.4^{*} p$-value $=0.022$}} \\
\hline Limit usage of sugar or sweets: & & & & & & & & \\
\hline Routinely & 104 & 75.9 & 54 & 55.7 & 117 & 60.9 & 275 & 64.6 \\
\hline Sometimes & 22 & 16.1 & 40 & 41.2 & 56 & 29.2 & 118 & 27.7 \\
\hline Never & 11 & 8.0 & 3 & 3.1 & 19 & 9.9 & 33 & 7.7 \\
\hline \multirow[t]{2}{*}{ Total } & \multirow{3}{*}{\multicolumn{8}{|c|}{$\xi^{2}=21.5^{*} p$-value $=0.000$}} \\
\hline & & & & & & & & \\
\hline Take excess salts in food: & & & & & & & & \\
\hline Routinely & 11 & 8.0 & 2 & 2.1 & 15 & 7.8 & 28 & 6.6 \\
\hline Sometimes & 24 & 17.5 & 34 & 35.1 & 61 & 31.8 & 119 & 27.9 \\
\hline Never & 102 & 74.5 & 61 & 62.9 & 116 & 60.4 & 279 & 65.5 \\
\hline \multirow[t]{2}{*}{ Total } & 137 & 100.0 & 97 & 100.0 & 192 & 100.0 & 426 & 100.0 \\
\hline & \multirow{2}{*}{\multicolumn{8}{|c|}{$\xi^{2}=14.5^{*} p$-value $=0.006$}} \\
\hline Eat fried food: & & & & & & & & \\
\hline Routinely & 8 & 5.8 & 7 & 7.2 & 20 & 10.4 & 35 & 8.2 \\
\hline Sometimes & 33 & 24.1 & 34 & 35.1 & 58 & 30.2 & 125 & 29.3 \\
\hline Never & 96 & 70.1 & 56 & 57.7 & 114 & 59.4 & 266 & 62.4 \\
\hline \multirow{2}{*}{ Total } & 137 & 100.0 & 97 & 100.0 & 192 & 100.0 & 426 & 100.0 \\
\hline & \multicolumn{8}{|c|}{$\xi^{2}=6.5 p$-value $=0.164$} \\
\hline Eat fresh vegetables: & & & & & & & & \\
\hline Routinely & 106 & 77.4 & 63 & 64.9 & 121 & 63.0 & 290 & 68.1 \\
\hline Sometimes & 21 & 15.3 & 32 & 33.0 & 52 & 27.1 & 105 & 24.6 \\
\hline Never & 10 & 7.3 & 2 & 2.1 & 19 & 9.9 & 31 & 7.3 \\
\hline \multirow[t]{2}{*}{ Total } & 137 & 100.0 & 97 & 100.0 & 192 & 100.0 & 426 & 100.0 \\
\hline & \multicolumn{8}{|c|}{$\xi^{2}=16.1 * p$-value $=0.003$} \\
\hline \multicolumn{9}{|l|}{ Eat fruits: } \\
\hline Routinely & 105 & 76.6 & 63 & 64.9 & 118 & 61.5 & 286 & 67.1 \\
\hline Sometimes & 22 & 16.1 & 31 & 32.0 & 59 & 30.7 & 112 & 26.3 \\
\hline Never & 10 & 7.3 & 3 & 3.1 & 15 & 7.8 & 28 & 6.6 \\
\hline \multirow[t]{2}{*}{ Total } & 137 & 100.0 & 97 & 100.0 & 192 & 100.0 & 426 & 100.0 \\
\hline & \multicolumn{8}{|c|}{$\xi^{2}=13.3 * p$-value $=0.010$} \\
\hline \multicolumn{9}{|l|}{ Eat meat and fish: } \\
\hline Routinely & 83 & 60.6 & 55 & 56.7 & 69 & 35.9 & 207 & 48.6 \\
\hline Sometimes & 47 & 34.3 & 37 & 38.1 & 101 & 52.6 & 185 & 43.4 \\
\hline Never & 7 & 5.1 & 5 & 5.2 & 22 & 11.5 & 34 & 8.0 \\
\hline \multirow[t]{2}{*}{ Total } & 137 & 100.0 & 97 & 100.0 & & 100.0 & 426 & 100.0 \\
\hline & \multicolumn{8}{|c|}{$\xi^{2}=24.0 * p$-value $=0.000$} \\
\hline
\end{tabular}

NB: (*) Statistically significant difference. 
Table (4): Physical exercise practices among the study sample regarding to sex.

\begin{tabular}{|c|c|c|c|c|c|c|}
\hline \multirow{2}{*}{ Variable } & \multicolumn{2}{|c|}{ Male } & \multicolumn{2}{|c|}{ Female } & \multicolumn{2}{|c|}{ Total } \\
\hline & No. & $\%$ & No. & $\%$ & No. & $\%$ \\
\hline \multicolumn{7}{|l|}{ Physical exercise: } \\
\hline Routinely & 225 & 69.4 & 52 & 51.0 & 277 & 65.0 \\
\hline Sometimes & 71 & 21.9 & 47 & 46.1 & 118 & 27.7 \\
\hline Never & 28 & 8.6 & 3 & 2.9 & 31 & 7.3 \\
\hline \multirow[t]{2}{*}{ Total } & 324 & 100.0 & 102 & 100.0 & 426 & 100.0 \\
\hline & \multicolumn{6}{|c|}{$\xi^{2}=24.0 * p$-value $=0.000$} \\
\hline \multicolumn{7}{|l|}{ Intensity of exercise: } \\
\hline Mild & 96 & 29.6 & 55 & 53.9 & 151 & 35.4 \\
\hline Moderate & 165 & 50.9 & 43 & 42.2 & 208 & 48.8 \\
\hline Vigorous & 35 & 10.8 & 1 & 1.0 & 36 & 8.5 \\
\hline Not Applicable & 28 & 8.6 & 3 & 2.9 & 31 & 7.3 \\
\hline \multirow[t]{2}{*}{ Total } & 324 & 100.0 & 102 & 100.0 & 426 & 100.0 \\
\hline & \multicolumn{6}{|c|}{$\xi^{2}=26.5 * p$-value $=0.000$} \\
\hline
\end{tabular}

NB: $(*)$ Statistically significant difference.

Table (5):Physical exercise practices among the study sample regarding to university years.

\begin{tabular}{|c|c|c|c|c|c|c|c|c|}
\hline \multirow{2}{*}{ Variable } & \multicolumn{8}{|c|}{ University year } \\
\hline & Second Grade & $\%$ & Third Grade & $\%$ & Final Grade & $\%$ & Total & $\%$ \\
\hline \multicolumn{9}{|l|}{ Physical exercise: } \\
\hline Routinely & 105 & 76.6 & 59 & 60.8 & 113 & 58.9 & 277 & 65.0 \\
\hline Sometimes & 22 & 16.1 & 34 & 35.1 & 62 & 32.3 & 118 & 27.7 \\
\hline Never & 10 & 7.3 & 4 & 4.1 & 17 & 8.9 & 31 & 7.3 \\
\hline \multirow[t]{2}{*}{ Total } & 137 & 100.0 & 97,2 & 100.0 & 192 & 100.0 & 426 & 100.0 \\
\hline & \multicolumn{8}{|c|}{$\xi^{2}=16.3 * p$-value $=0.003$} \\
\hline \multicolumn{9}{|l|}{ Intensity of exercise: } \\
\hline Mild & 40 & 29.2 & 44 & 45.4 & 67 & 34.9 & 151 & 35.4 \\
\hline Moderate & 70 & 51.1 & 42 & 43.3 & 96 & 50.0 & 208 & 48.8 \\
\hline Vigorous & 15 & 10.9 & 8 & 8.2 & 13 & 6.8 & 36 & 8.5 \\
\hline Not Applicable & 12 & 8.8 & 3 & 3.1 & 16 & 8.3 & 31 & 7.3 \\
\hline \multirow[t]{2}{*}{ Total } & 137 & 100.0 & 97 & 100.0 & 192 & 100.0 & 426 & 100.0 \\
\hline & \multicolumn{8}{|c|}{$\xi^{2}=9.7 p$-value $=0.137$} \\
\hline
\end{tabular}

NB: (*) Statistically significant difference.

Table (6): lifestyle behaviour factors among the studied sample regard to sex.

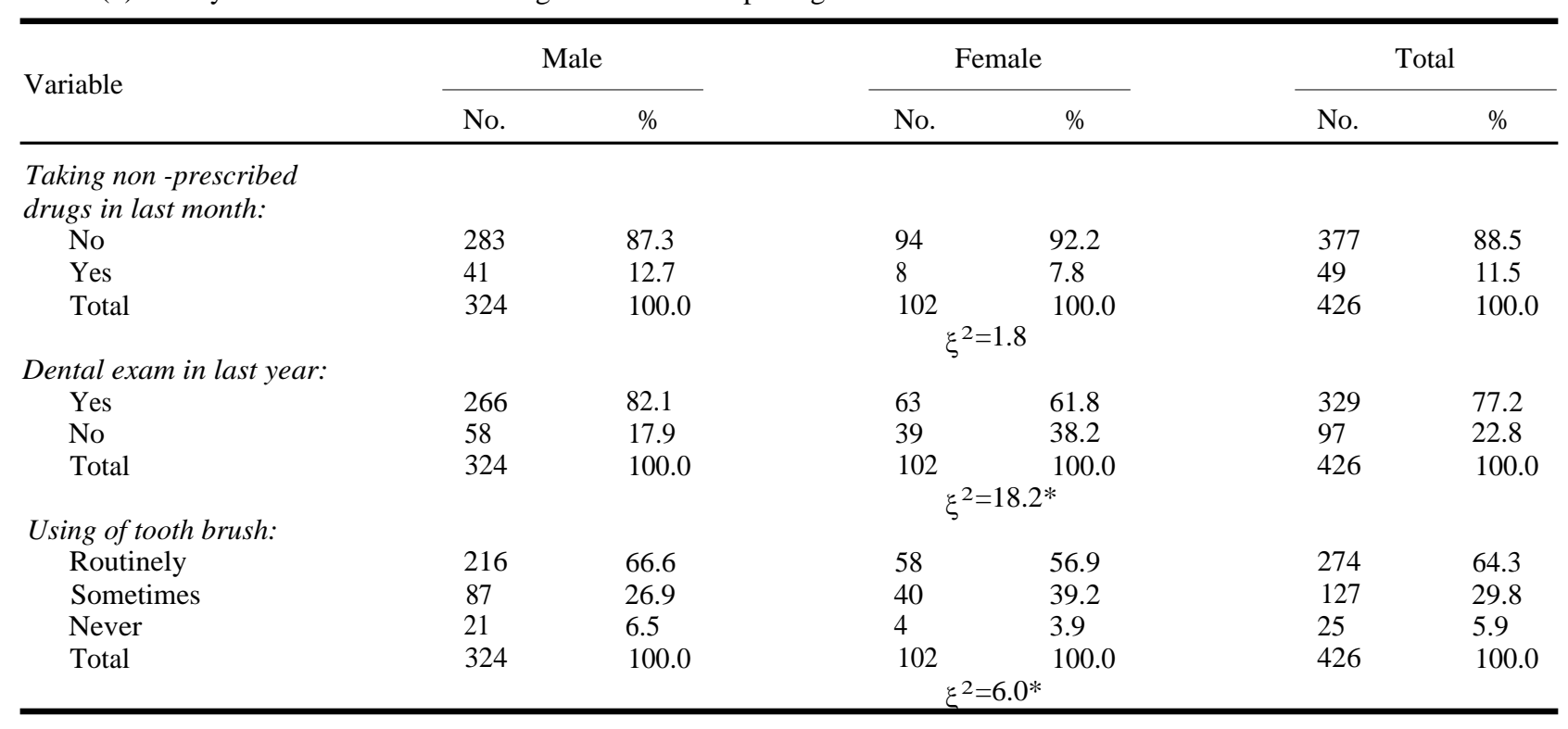


Table (7): lifestyle behaviour factors among the study sampleregard to age.

\begin{tabular}{|c|c|c|c|c|c|c|c|c|}
\hline \multirow{2}{*}{ Variable } & \multicolumn{8}{|c|}{ Age of student } \\
\hline & $(-20)$ No & $\%$ & $(20-)$ No & $\%$ & $(24+)$ No & $\%$ & Total & $\%$ \\
\hline \multicolumn{9}{|l|}{ Smoking habits: } \\
\hline Non Smoker & 13 & 92.9 & 350 & 95.6 & 44 & 95.7 & 407 & 95.5 \\
\hline Smoker & 1 & 7.1 & 16 & 4.4 & 2 & 4.3 & 19 & 4.5 \\
\hline Total & 14 & 100.0 & 366 & 100.0 & 46 & 100.0 & 426 & 100.0 \\
\hline \multicolumn{9}{|c|}{$x^{2}=0.3 p$-value $=0.885$} \\
\hline \multicolumn{9}{|l|}{ Dietary habits: } \\
\hline Healthy & 12 & 85.7 & 242 & 66.1 & 23 & 50.0 & 277 & 65.0 \\
\hline Unhealthy & 2 & 14.3 & 124 & 33.9 & 23 & 50.0 & 149 & 35.0 \\
\hline Total & 14 & 100.0 & 366 & 100.0 & 46 & 100.0 & 426 & 100.0 \\
\hline \multicolumn{9}{|c|}{$x^{2}=7.4 * p$-value $=0.025$} \\
\hline Physical exercise & & & & & & & & \\
\hline Practice & 11 & 78.6 & 217 & 59.3 & 18 & 39.1 & 246 & 57.7 \\
\hline Not Practice & 3 & 21.4 & 149 & 40.7 & 28 & 60.9 & 180 & 42.3 \\
\hline Total & 14 & 100.0 & 2366 & 100.0 & 46 & 100.0 & 426 & 100.0 \\
\hline \multicolumn{9}{|c|}{$X^{2}=9.4 * p$-value $=0.009$} \\
\hline
\end{tabular}

NB: (*) Statistically significant difference.

\section{Discussion}

Our results on Socio-demographic characteristics of the studied sample cleared that, the highest percentage $(85.9 \%)$ of the students was in the age group (20-24) years and the lowest percentage $(3.3 \%)$ was in the age group ( $<20$ years). No statistically significant difference between students' males and females regarding age. The majorities $(45 \%)$ of the total students were in the final year, $(40.1 \%)$ were males and $(4.9 \%)$ were females.

Regarding the age group of the study sample, our result agreed with those of the study conducted by Okafor et al., [10] who shows that the largest percentage was among the study sample with the age group of $20-24$ (47.9\%).

As regards living place, more than two-thirds of the total students $(67.1 \%$ ) were living in students hostel, while (2.1\%) of them were living alone, the difference was statistically significant between students male and females.

On other hand, our results agree with the study of Hanawi et al., [11], which revealed that Most of the participants live in campus (80.9\%), $11.6 \%$ live in rented houses, and $7.5 \%$ with family.

In contrary to our results, Bhuiyan et al., [12], show that $36.4 \%$ of the participants were staying with family while the majority of them were not $(63.6 \%)$.

Regarding working status, the lowest percentage $(20.9 \%)$ they worked beside study $(19.5 \%)$ were males and $(1.4 \%)$ were females. Meanwhile, re- garding family income, our results cleared that, show that around two-thirds of students $(67.6 \%)$ reported they had average family income and $(5.9 \%)$ of them reported insufficient family income.

Similar to ours, Msoga and Anase [13], found in their study that the majority (63.0\%) considered themselves as coming from average income families, $23.0 \%$ considered themselves coming from well off families and $14.0 \%$ considered themselves coming from poor families.

Also, Haider et al., [14] reported that about $84 \%$ of graduate students belong to an urban area and had average family income, and $16 \%$ belong to the rural areas of a university. Findings of this study are consistent to the study reported by Salahuddin and Talukder [15] and that conducted by Miller and Birch [16] where they concluded, on average academic performance of graduate students with respect to their residential area are equal.

Meanwhile, our results on the food consumption pattern among the study sample regarding to sex, cleared that, the highest percentage of male and female students who used to eating breakfast regularly was $(70.1 \%)$ and $(58.8 \%)$, respectively, while the lowest percentage among male and female students who did not use to eating breakfast regularly (7.4\%) and (5.9\%) respectively.

Ackuaku-Dogbe and Abaidoo [17] show that the prevalence of breakfast skipping among females was significantly higher $(74.56 \%$ ) than in males $(70.44 \%)$. Also, Mohammed [18] mentioned that the Students who skipped their breakfast were $80 \%$. 
Our results agree with the study done by Vinita et al., [19], who stated that for regular breakfast consumers, significantly ( $p=0.001)$ more male students (19\%) had late breakfast (around 10-11 a.m.) than female students (4.9\%). Female students $(56.2 \%)$ started skipping breakfast after starting college, while male students $(54.1 \%)$ started skipping breakfast at school.

Our results illustrated that the percentage between male and female students who used to routinely eat limited amounts of sugar or sweets was $(67.3 \%)$ and $(55.9 \%)$, respectively, while the percentage between male and female students who did not use sugar or sweets was $(9.0 \%)$ and $(3.9 \%)$ respectively, the difference was statistically significant. On the other hand, the majority of male and female students reported that they were avoiding use excess salt in food was $(66.7 \%) \&(61.8 \%)$ respectively, while a small proportion of male and female students who reported that they using excess salt in food was $(8.0 \%) \&(2.0 \%)$ respectively.

Niba et al., [20] reported that the consumption of sugar-sweetened beverages (twice or more times a week) was common among the students (39.5\%), there was no significant difference between males and females. The proportion of those who consumed beans at least twice a week was significantly higher for males $(23.5 \%)$ than females $(17.8 \%)$. A significant difference in the consumption of fried foods by gender was reported for fried Irish potatoes. More than half $(53.4 \%)$ of the participants ate fried foods (fried Irish potatoes and plantain) twice or more times a week. The consumption of fried food five or more times a week was more common among females $(9.5 \%)$ than males $(6.2 \%)$.

Our results agreed with those of Biswas et al., [21] about (29.9\%) of the respondents had knowledge regarding the health effects of dietary salt intake, and $87.8 \%$ perceived that dietary salt reduction was important. More than half (52.4\%) thought that they were taking the right amount of salt or less. Only $4.1 \%$ perceived that they consume too much dietary salt. The majority $(93.2 \%)$ responded positively when they were asked if they knew about the health problems that excess salt consumption can create. More than two-thirds of the respondents $(70.7 \%$ including always, often, and sometimes) consumed processed foods containing a high levels of salt. More than seven out of ten $(72.8 \%)$ of the students were avoiding processed food as their control activity of salt intake habit.

Our study illustrated that eating fresh vegetables and $\&$ fruits routinely. The percentage of male students of the study sample who were eating meat and fish routinely was $(46.9 \%)$, while in female students was $(53.9 \%)$.

In line with our study, about $(89.5 \%)$ of subjects likes fruits and vegetables. (96.9\%) of students reported that eating fruits and vegetables makes them feeling healthy, while $(89.5 \%)$ considered fruits and vegetables as having a good taste. $(92.7 \%)$ of the students believe that eating fruits and vegetables gives them more energy. (91.2\%) believe it is healthier to eat fruits than juices, while $(37.1 \%)$ don't believe that avoiding fruits and vegetables would make them unhealthy, $(10 \%)$ don't believe that fruits and vegetables reduce chronic disease risk [22]

In terms of meat and fish consumption Hosu et al., [23] found that a total of $80 \%$ of male students (aged 18 to 38) in BDU consumed more than the recommended meat intake (52g and $56 \mathrm{~g}$ ) per day. Despite the fact that gender class at both colleges reflects the peculiarities of consuming the required amount of meat per day, female students consume less meat $(46 g)$ per day than their male counterparts.

Also, we found the percentage of students who used to eating breakfast regularly was higher among students of the second grade (76.6\%), compared to the students of the third grade $(62.9 \%)$ and the final grade $(63.0 \%)$, the difference was statistically significant. The percentage between the study samples who used to routinely eat limit amounts of sugar or sweets was (75.9\%) among the secondgrade students, compared to the students of the third grade $(55.7 \%)$ and the final year $(60.9 \%)$.

Alzahrani et al., [24] observed that the total eating score was compared across categorical variables significant for the following factors: Different academic years, with the greatest scores in the sixth year and the lowest scores in the fifth year.

We found about three fourth of the studied sample of second-grade students were consuming fresh vegetables \& fruits routinely, on other hand about two-third of the students of the third grade and the final grade were consuming fresh vegetables $\&$ fruits routinely. The percentage of the study sample that never ate meat and fish was more among students in the final grade $(11.5 \%)$.

In agreement with our results Nola et al., [25] who Studied eating and lifestyle habits of first $(\mathrm{n}=169)$ and sixth $(\mathrm{n}=272)$ year students, aged 18 to 26 years, attending a Medical School in Zagreb, were compared related to the years of study. Both 
year students reported a similar number of meals per day, irregular consumption of meals, skipping breakfast, frequency of vegetables, fruits, cereals, sweets, milk, and dairy products consumption.

Regarding physical exercise routinely among the study sample, our study revealed that, the highest percentage $(69.4 \%)$ was found among male students, while less proportion (51.0\%) among female students, the difference was statistically significant. According to intensity of exercise, the percentage of moderate physical exercise was higher among male students (50.9\%). Compared to $(42.2 \%)$ in female students.

Bianchini de Quadros et al., [26] found that the prevalence of physical inactivity was $13.8 \%$ among the university freshmen being studied, a higher percentage of female students being inactive than male students.

Our study was supported by Vinita et al., [19] where the highest percentage was found among male students (30\%), while (11.3\%) among female students who practice physical activity every day.

Our findings are consistent with those of ElNimr et al., [27] who found that more than half of students $(56 \%)$ reported engaging in physical exercise, with a statistically significant difference between males and girls ( $73.2 \%$ of males versus $39.1 \%$ of females, $2=47.252, p<0.001$ ).

Our study demonstrated that the highest percentage of the study sample who was engaged in physical exercise routinely $(76.6 \%)$ was found among second-grade students, while less proportion (58.9\%) among final grade students, the difference regarding physical exercise was statistically significant. According to intensity of exercise, the percentage of vigorous exercise was higher among second-grade students $(10.9 \%)$ compared to other grades.

In addition, Lipo s ek et al., [28] revealed that binary logistic regression was used to examine the impact of physical exercise on academic success. Academically, the majority of students was successful and was usually admitted to the second year of study $(86.5 \%)$. Regular entrance to the second year of study was influenced by two or three hours of weekly physical activity.

In the present study, we found that $(82.1 \%)$ of male students perform a dental examination in the last year compared to $(61.8 \%)$ of female students, with a statistically significant difference. Regarding using of toothbrushes.
In addition, Barnabas [29] reported that females had much more dental appointments and paid more attention to their oral health than males $(52.5 \%$ vs. $28.1 \%$, respectively). Females, compared to males, used a medium-strength toothbrush and brushed their teeth more frequently $(90.0 \%$ vs. $52.6 \%)$.

Unlike our findings, Halawany et al., [30] found that a higher percentage of females $(71.8 \%)$ than males $(51.3 \%)$ reported brushing their teeth twice a day on average. The behavior of males and females when brushing their teeth.

In our results we found that above $(95.5 \%)$ of the different age groups of the studied samples were nonsmokers, the difference was statistically insignificant. The behavior concerned with healthy dietary habits was more prevalent among students under 20 years $(85.7 \%)$ compared to $(66.1 \%)$ of students between $20 \& 24$ years and $(50.0 \%)$ of students above 24 years with a statistically significant difference. The percentage of studied samples who practiced physical exercise was greater among students under 20 years (78.6\%) compared to $(59.3 \%)$ among students between $20 \& 24$ years and $(39.1 \%)$ among students above 24 years.

Smoking prevalence is highest among young adults: $23 \%$ of those aged $16-24$ and $24 \%$ among the 25-34 age groups [31].

Furthermore, Nasser and Zhang [32] discovered that smoking prevalence was higher $(p<0.001)$ among students older than 24 years old; the prevalence was $54.5 \%$ in students older than 24 years old vs. $44.8 \%$ in students younger than 18 years old, and $21.0 \%$ in students aged $18-24$ years old. Seniors in their third and fourth years were significantly more likely than juniors to smoke.

Regarding to healthy dietary habits, the university students reported $2.86 \pm 1.139$ healthy dietary practices, according to their age $[\mathrm{t}(825)=2.377$, $p=0.018]$ and residence $[\mathrm{t}(814)=4.590, p=0.000]$ [33]. Regular engagement in sports practice was higher in boys than girls in all age groups [34]

\section{Conclusions:}

- The majority of study sample among students were in final year, In terms of living arrangements, more than two-thirds of all students were lived in a student hostel.

- Around two-thirds of students said their family income was average. Meanwhile, the majority of study sample among students said their family size was (3-5) members, In terms of their parents' education; however, there is no statistically sig- 
nificant difference between male and female of the study sample.

- The percentage of male students who were eating breakfast routinely \& were eating limit amounts of sugar or sweets routinely \& were avoiding use excess salt in food routinely was higher more than females.

- The percentage of female students who were eating meat \& fish routinely was higher more than male. Conversely the percentage of male students who were eating fruits \& vegetables routinely was higher more than females.

- About two-thirds of male students (65.4\%) were never drinking tea or coffee, while $39.2 \%$ of female students. The proportion of male and female students in the study sample who were drinking soda was $(59.0 \%)$ and $(58.8 \%)$, respectively.

- The percentage of students who were eating breakfast routinely $(76.6 \%) \&$ who were eating limit amounts of sugar or sweets was $(75.9 \%)$ was higher among students in the second grade compared to students in other grades.

- The highest percentage regarding to practices of physical activity and moderate intensity of exercise was among male students of the study sample.

- The highest percentage regarding to practices of physical activity and moderate intensity of exercise was among students of second grade the study sample compare to students of other grades.

- Among the study sample the highest percentage regarding to good oral hygiene was among male students compare to female students.

- Regarding to dental examination in the last year \& using of toothbrush the highest percentage among the study sample was among second grade compare to other grades.

- The percentage of non-smokers was more than 90\% among students of different age group, the students of age group (-20) had the highest percentage of eating healthy food and practicing physical exercise than other students.

\section{Recommendations:}

Based on the results of this study, this study recommends the following:

- Establishment of committees in the university to achieve the health needs of the students and try to help them in monitoring their health behaviors through measurement of their healthy lifestyle and give them advice for changing their health behaviors to desirable ones.

- Enhancements physical education programs in the university in order to upgrade the physical activity of college students.

- Integration of healthy lifestyle education into the formal primary and secondary school educational program.

- Promotion of healthy lifestyle behaviors via mass media campaigns, school-based interventions, and healthcare interventions tailored to the needs of lower socioeconomic groups.

- Activate the role of awareness about hazards of unhealthy lifestyle behaviors among students and their impact on their health in the future.

- Implementation of the anti-smoking program among university students.

- Further researches targeting the impact of healthy lifestyle behaviors should be conducted among other students in different colleges.

\section{References}

1- KELLY-WEEDER S.: Binge drinking in college-aged women: Framing a gender-specific prevention strategy. J. Am. Acad. Nurse Pract., 20: 577-584, 2010.

2- MONTAZERI N., KIANIPOUR N., NAZARI B., ZIAPOUR A. and BAKHSHI S.: Health Promoting Behaviors among University Students: A Case-Sectional Study of Kermanshah University of Medical Sciences. Int. J. Pediatr., 5 (6): 5091-99, 2017.

3- PATEL P.H., MALGAONKAR A.A. and KARTIKEYAN S.: Cross-sectional descriptive study of lifestyle patterns of undergraduate medical students in a metropolitan Medical College. Int. J. Community Med. Public Health, 3 (10): 2866-2873, 2016.

4- HUNT J. and EISENBERG D.: Mental health problems and help-seeking behavior among college students. Journal of Adolescent Health, 46 (1): 3-10, 2010.

5- FOROUZANFAR M.H., ALEXANDER L., ANDERSON H.R., BACHMAN V.F. and BIRYUKOV S.: Global, regional, and national comparative risk assessment of 79 behavioural, environmental and occupational, and metabolic risks or clusters of risks in 188 countries, 19902013: A systematic analysis for the Global Burden of Disease Study 2013. The Lancet, 386: 2287-323, 2015.

6- MEHRI A., SOLHI M., GARMAROUDI G., NADRIAN H. and SIGHALDEH S.: Health promoting lifestyle and its determinants among University students in Sabzevar, Iran. International Journal of Preventive Medicine, 7 (1): 65-71, 2016.

7- AL-NAKEEB Y., LYONS M., DODD L. and AL-NUAIM A.: An Investigation into the Lifestyle, Health Habits and Risk Factors of Young Adults. International Journal of Environmental Research and Public Health, 12 (4): 43804394, 2015. 
8- HAC1HASANOGLU R, Y1LD1R1M A., KARAKURT P. and SAGLAM R.: Healthy lifestyle behaviour in university students and influential factors in eastern Turkey. International Journal of Nursing Practice, 17 (1): 43-51, 2011.

9- WANG C and COUPS E.: Causal beliefs about obesity and associated health behaviors: results from a populationbased survey. International Journal of Behavioral Nutrition and Physical Activity, 7 (1): 19-25, 2010.

10- OKAFOR N., ASUQUO E., NKPORBU A., OKECHUKWU C. and ONOH I.: Socio-demographic characteristics and other factors associated with depressive illness among medical students at the University of Port Harcourt. Insights on the Depression and Anxiety, 4 (1): 040-048, 2020.

11- HANAWI S.A., SAAT N.Z., ZULKAFLY M., HAZLENAH H., TAIBUKAHN N.H., YOGANATHAN D. and LOW F.J.: Impact of a Healthy Lifestyle on the Psychological Well-being of University Students. International Journal of Pharmaceutical Research and Allied Sciences, 9 (2): 142-148, 2020.

12- BHUIYAN M., SHENG J.W., GHAZALI F.H., AL MUGHASBI F.G., ARNOUS M.K., MAZIZ M.N. and KADIR S.Y.: Health-promoting lifestyle habits among preclinical medical students. Pakistan Journal of Medical and Health Sciences, 11 (2): 490-495, 2017.

13- MSOGA J. and ANASEL M.: The relationship between eating habits, socio-demographic characteristics and body mass index among undergraduate students from two selected universities, Tanzania. International Journal of Community Medicine and Public Health, 7 (2): 406-15, 2020.

14- HAIDER Z., ALI S., MUNIR F., KHAN H. and AHMED A.: Factors contributing to the students academic performance: A case study of Islamia University Sub-Campus American Journal of Educational Research, 1 (8): 283289, 2013.

15- SALAHUDDIN S. and TALUKDER M.H.: Influence of Socio-Demographic Characteristics on Academic Performance of Medical Students. Bangladesh Journal of Medical Education, 8 (2): 18-23, 2017.

16- MILLER P. and BIRCH E.: The influence of type of high school attended on university performance. Australian Economic Papers, 46 (1): 1-17, 2010.

17- ACKUAKU-DOGBE E. and ABAIDOO B.: Breakfast Eating Habits among Medical Students. Ghana Medical Journal, 48 (2): 66-71, 2014.

18-MOHAMMED S.: Breakfast Consumption Patterns among the Students at Ahfad University for Women. Edelweiss Applied Science and Technology, 4 (1): 33-37, 2020.

19- VINITA M., AMRITHA A., DHARANI B., TEJASRI S. and MAHESWARI S.: Assessment of breakfast skipping and health-compromising behaviours among college students in chennai. JIDAM, 6 (3): 80-87, 2019.

20- NIBA L., ATANGA M. and NAVTI L.: A cross sectional analysis of eating habits and weight status of university students in urban Cameroon. BMC Nutrition, 3 (1): 1-8, 2017.

21- BISWAS J., HAQUE M., MAHBUB M., NURANI R., SHAH N. and BARUA L.: Salt intake behavior among the undergraduate students of Bangladesh University of
Health Sciences. Journal of Xiangya Medicine, 5 (2): 2424, 2020.

22- OMAR M., NOUH F., YOUNIS M., YOUNIS M., EBRAHIM T. and SALIM W.: Fruits and vegetables consumption among Benghazi university students. SAS Journal, 3: 299-306, 2017.

23- HOSU Y.S., AROWOLO A.S. and FAYEMI P.O.: Determinants of meat consumption pattern among university students in the Eastern Cape Province of South Africa. African Journal of Agricultural Research, 10 (27): 26422650, 2015.

24- ALZAHRANI S.H., SAEEDI A.A., BAAMER M.K., SHALABIA.F. and ALZAHRANI A.M.: Eating habits among medical students at King Abdulaziz University, Jeddah, Saudi Arabia. International Journal of General Medicine, 13 (2): 77-83, 2020.

25- NOLA I.A., DOKO JELINIC' J., MATANIC' D., PUCARIN-CVETKOVIC' J., BERGMAN MARKOVIC'B and SENTA A.: Differences in eating and lifestyle habits between first-and sixth-year medical students from Zagreb. Collegium Antropologicum, 34 (4): 1289-1294, 2010.

26- BIANCHINI DE QUADROS T.M., PETROSKI E.L., SANTOS-SILVA D.A. and PINHEIRO-GORDIA A.: The prevalence of physical inactivity amongst Brazilian university students: Its association with sociodemographic variables. Revista de Salud Pública, 11 (5): 724-733, 2011.

27- EL-NIMR N.A., BASSIOUNY S.H. and TAYEL D.I.: Pattern of caffeine consumption among university students. Journal of High Institute of Public Health, 49 (3): 154$161,2019$.

28- LIPOSEK S., PLANINSEC J., LESKOSEK B. and PAJTLER A.: Physical activity of university students and its relation to physical fitness and academic success. Annales Kinesiologiae, 9 (2): 89-104, 2018.

29- BARNABAS U.: Gender difference in oral health perception and practices among Medical House Officers. Russian Open Medical Journal, 1 (2): 212-219, 2012.

30- HALAWANY H., ABRAHAM N., JACOB V. and ALMAFLEHI N.: The perceived concepts of oral health attitudes and behaviors of dental students from four Asian countries. The Saudi Journal for Dental Research, 6 (2): 79-85, 2015.

31- AL ATTAR K., KONCHWALLA F., IBIROGBA E.R., SALAM J., ABDALLA K. and AL SHARBATTI S.: Prevalence of Healthy Lifestyles In Health Science Students and Healthcare Professionals In Ajman, Uae GMJ. ASM, 5 (1): 82-93, 2016.

32- NASSER A. and ZHANG X.: Knowledge and factors related to smoking among university students at Hodeidah University, Yemen. Tobacco Induced Diseases, 17 (5): 227-232, 2019.

33- ALVES R.F., PRECIOSO J. and BECOÑA E.: Knowledge, attitude and practice on healthy diet among University Students in Portugal. Healthy dietary habits of university students. Int. J. Nutr. Sci., 5 (2): 136-142, 2020.

34- CHRISTOFARO D., FERNANDES R., MARTINS C., RONQUE E., COELHO-E-SILVA M., SILVA A., SARDINHA L. and CYRINO E.: Prevalence of physical activity through the practice of sports among adolescents from Portuguese speaking countries. Ciência and Saúde Coletiva, 20 (4): 1199-1206, 2015. 


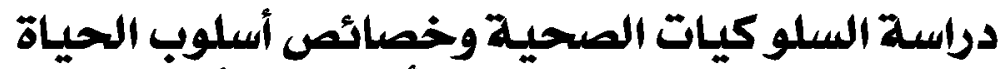

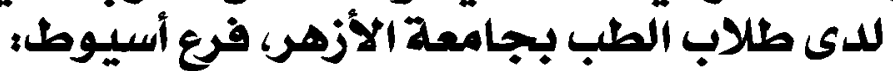 \\ دراسلة بحثية}

خلفية البحث: أسلوب الحياة هو طريقة حياة الأفراد والعائلات والمجتمعات التى يمكن أن تكون صحية أو غير صحية من حيث السلوكيات

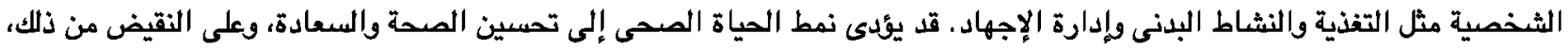

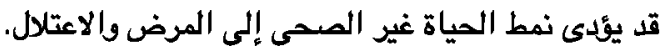

الهدف من البحث: معرفة العلاقة بين متغيرات سلوك نمط الحياة الصحى لعينة الدراسة وجنس الطلاب والسنوات الجامعية.

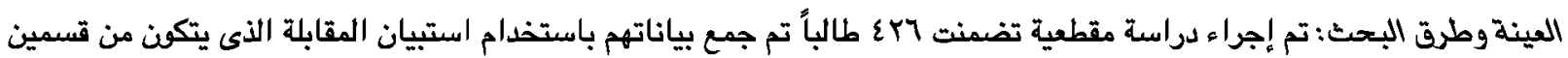

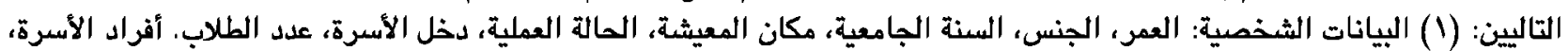

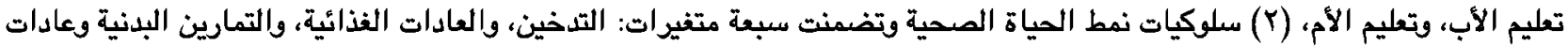

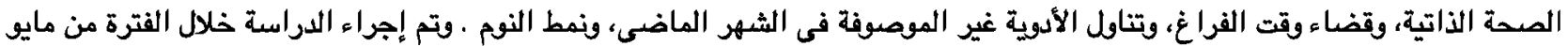

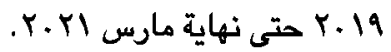

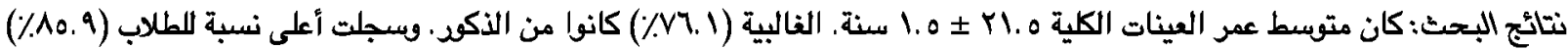

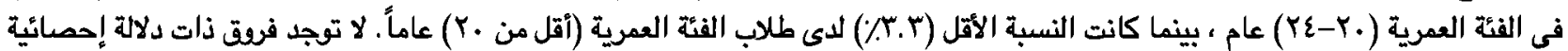

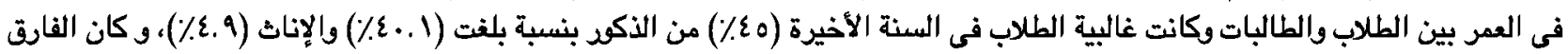
ذو دلالة إحصائية.

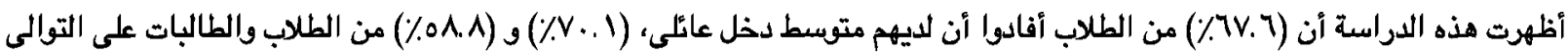

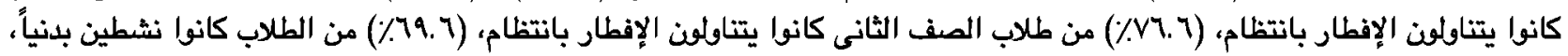

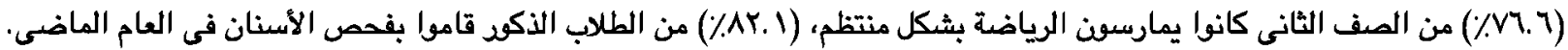

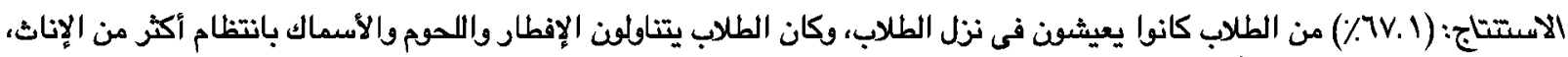

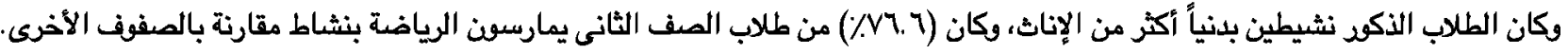

